\title{
Characteristics of Summertime Afternoon Rainfall and Its Environmental Conditions in and around the Nobi Plain
}

\author{
Tetsuya Takemi \\ Disaster Prevention Research Institute, Kyoto University, Uji, Kyoto, Japan
}

\begin{abstract}
This study investigates the characteristics of local-scale afternoon rainfall and its environmental conditions in and around the Nobi Plain under synoptically undisturbed conditions in summer by using operational meteorological data. The analysis of radar/ raingauge analyzed precipitation data revealed that strong rainfall occurs over the mountain slopes in late afternoon and in the northern part of the Nobi Plain in early evening, while light rain frequently occurs around the mountain peaks in early afternoon. Examining mesoscal analysis data indicated that the primary difference in the environmental conditions that distinguish between rain and no-rain days is middle-level moisture field, with moister condition being found on rain days. Because of the significant difference in the middle-level moisture, stability index is useful in distinguishing the environmental conditions between rain and norain days.
\end{abstract}

(Citation: Takemi, T., 2014: Characteristics of summertime afternoon rainfall and its environmental conditions in and around the Nobi Plain. SOLA, 10, 158-162, doi:10.2151/sola.2014-033.)

\section{Introduction}

Afternoon rain events in summer often develop locally and rapidly, caused by thunderstorms, and contain rich scientific interest. Recent studies on thunderstorms in the Tokyo area have been gaining significant advances on the understanding of local-scale rain events (Kobayashi et al. 2011; Sakurai et al. 2012; Saito et al. 2013; Shoji 2013).

At the same time, the statistical analysis of such rain events and their environmental conditions is important to understand the general characteristics of those rain events. There are studies to investigate the environmental conditions for the development of summertime thunderstorms in the Kanto Plain (Yonetani 1975; Taguchi et al. 2002; Kawano et al. 2004; Nomura and Takemi 2011, hereafter referred to as NT11). NT11 used the analysis data produced by the operational Mesoscale Model (MSM) of Japan Meteorological Agency (JMA) to examine the environmental stability for afternoon rain events in the Kanto Plain in summer and indicated that colder temperature at middle levels and higher moisture at low and middle levels are favorable conditions for the rain events.

Although there are a large number of studies which investigated local-scale rain events in the Kanto Plain, a very limited number of studies have dealt with those occur in the Nobi Plain. Sano and Tsuboki (2006) examined the structure and evolution of a cumulonimbus cloud on the mountain slope to the north of the Nobi Plain and indicated a role of valley wind and sea breeze in initiating the cumulonimbus. Obana (1977) examined the local characteristics of strong precipitation in and around the Nobi Plain; this study is regarded as an initial attempt to make use of data obtained by surface observation network (Automated Meteorological Data Acquisition System; AMeDAS) and weather radar. Kuwagata (1997) investigated summer rainfalls in central Japan under fair-weather conditions in 1985 by using the AMeDAS

Corresponding author: Tetsuya Takemi, Disaster Prevention Research Institute, Kyoto University, Gokasho, Uji, Kyoto 611-0011, Japan. E-mail: takemi@storm.dpri.kyoto-u.ac.jp. (C)2014, the Meteorological Society of Japan. data and showed that the rain showers frequently develop in the mountainous regions under conditions with high precipitable water vapor. He suggested that the rain showers are resulted from thermally induced circulation over the central mountains. However, because of the limited dataset used in these studies, it is not known on the general characteristics of local-scale rain events in and around the Nobi Plain and their environmental conditions.

This study investigates the characteristics and the environmental conditions of the summertime afternoon rainfalls in and around the Nobi Plain. We specifically focus on the rain events that occur under synoptically undisturbed conditions in order to understand the general behavior of local-scale, convective rainfall in summer from a climatological point of view. For this purpose, we use a long-term operational meteorological dataset including MSM, AMeDAS, and radar/raingauge analyzed precipitation data from 2003 to 2010 .

\section{Data and analysis procedure}

The analysis area is the Nobi Plain and the surrounding area (i.e., $34.5^{\circ} \mathrm{N}-36.5^{\circ} \mathrm{N}, 136.0^{\circ} \mathrm{E}-138^{\circ} \mathrm{E}$ ). Figure 1a shows the map of the analysis area in which the dashed box is referred to as the area of the Nobi Plain, which is enlarged in Fig. 1b. Data used here are radar/raingauge analyzed precipitation (hereafter simply referred to as analysis precipitation) (Nagata 2011), surface observations at the AMeDAS sites (Fig. 1a), MSM analyses on the initial fields, and radiosonde observations at the Hamamatsu site (Fig. 1a). The analysis period is July and August from 2003 to 2010. During this analysis period, there was an update on the resolution of analysis precipitation: the analysis precipitation data have a horizontal resolution of $1.0 \mathrm{~km}$ after 2006, which is adjusted to the $2.5-\mathrm{km}$ resolution before 2005 . The AMeDAS sites shown in Fig. 1b are located over the plain area whose elevation is less than $100 \mathrm{~m}$. Note that the AMeDAS rainfall here is defined as the amount of precipitation during a previous hour.

According to NT11, the days under synoptically undisturbed

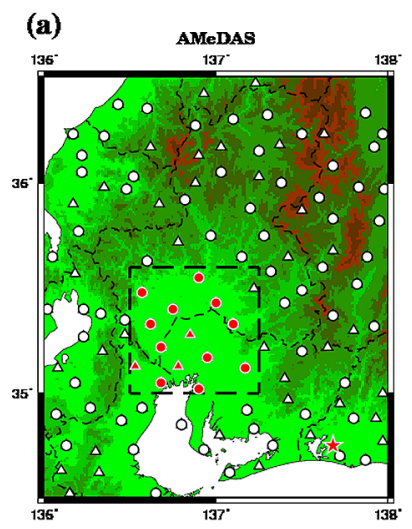

(b) AMeDAS (Nobi Pluin)

Fig. 1. (a) The map of the Nobi Plain and its surroundings for the present analysis, and (b) the locations of the AMeDAS sites whose elevations are below $100 \mathrm{~m}$ within the Nobi Plain. The circles and triangles indicate the AMeDAS sites (the triangles denote the AMeDAS sites where only precipitation data are obtained): the red marks mean the locations within the Nobi Plain below the 100-m elevation, and the white the other locations. The dashed-line box indicates the area of the Nobi Plain. The red star denotes the location of the Hamamatsu site. 
conditions are extracted out of all the days of July and August during 2003 and 2010 by the following steps. At first, the days within the Baiu period determined by JMA are excluded; 326 days out of 496 days are extracted. Secondly, the days when the centers of typhoons from the best-track data of JMA were located within the area of $30^{\circ} \mathrm{N}-40^{\circ} \mathrm{N}$ and $130^{\circ} \mathrm{E}-140^{\circ} \mathrm{E}$ are excluded; 36 days are eliminated. Thirdly, weather maps for the extracted days are examined to exclude days with lows and fronts within the area of $30^{\circ} \mathrm{N}-40^{\circ} \mathrm{N}$ and $130^{\circ} \mathrm{E}-140^{\circ} \mathrm{E} ; 153$ days are eliminated. After these steps, 137 days are extracted. The extracted 137 days are regarded as synoptically undisturbed cases.

The overall characteristics of rainfall in and around the Nobi Plain under synoptically undisturbed conditions are at first demonstrated with the use of analysis precipitation data. The performance of the analysis precipitation in representing surface-based measurements of rainfall at the AMeDAS sites was examined, and it was validated that the analysis precipitation data are useful in investigating the spatial and temporal variation of rainfall in and around the Nobi Plain. Next, the environmental conditions for the occurrence of rainfalls are examined by comparing with those for no-rainfall cases. For this purpose, the 137 days extracted are divided into the days with rainfall in the Nobi Plain in the afternoon (rain day; referred to as R) and the days without rainfall (fair-weather day; referred to as F), based on NT11. The $\mathrm{R}$ days are defined as having rainfall of greater than $1 \mathrm{~mm}$ at any AMeDAS sites in the Nobi Plain area from 1200 Japan Standard Time (JST; UTC plus 9 hours) to 0000 JST and having no rainfall at all these AMeDAS sites from 0600 JST to 1200 JST, while the $\mathrm{F}$ days as having no rainfall at all the AMeDAS sites in the Nobi Plain at all the times. The number of the $\mathrm{R}$ and the $\mathrm{F}$ days are 26 and 75 , respectively. The $\mathrm{F}$ days will be further divided in two patterns, which will be described in Section 4. It is noted that the days which are not categorized both in $\mathrm{R}$ and $\mathrm{F}$ days are characterized by light rainfall sometime between 0000 and 1200 JST (continuous from the previous night) and basically no rainfall afterwards in a day.

The MSM analyses at 0900 JST are used to examine the environmental conditions before the development of afternoon rainfalls. The representativeness of the MSM analyses at 0900 JST is validated against the upper-air observations at Hamamatsu for the 137 extracted days (see Supplement 1). The correlation coefficients between the observations and the analyses exceed 0.8 for temperature and 0.9 for the zonal and meridional components of wind speed. Although the correlation of relative humidity is generally lower than that of temperature and wind components, it is high at the 700 and $500-\mathrm{hPa}$ levels than at the lowest and the highest level shown in Fig. S2 of Supplement 1. Overall the performance of the MSM analyses in representing the observed states is good, which indicates that the MSM analyses are useful in examining the environmental conditions.

\section{Characteristics of afternoon rainfall}

The frequency distribution of hourly rainfall in and around the Nobi Plain from the analysis precipitation at the selected four times is shown in Fig. 2. The frequency is calculated by the number of the times of observed rainfall intensity that is greater than or equal to $1 \mathrm{~mm} \mathrm{~h}^{-1}$ among the extracted 137 days. At 1300 JST the development of scattered rainfall is seen on and around mountain peaks surrounding the Nobi Plain. Rainfall areas extend over the whole mountainous region at 1600 JST. The high frequency of rainfall over the mountainous region continues at the early evening hour (1900 JST), and at the same time there is an increased frequency in the northern part of the Nobi Plain. At 2200 JST the peak of the highest frequency seems to be migrated southward from the previous hours; the enhanced frequency of rainfall continues and extends over the Nobi Plain.

Figure 2 also indicates the surface wind fields by AMeDAS averaged for the extracted days. Over the Nobi Plain sea breeze from the Ise Bay develops and it turns eastward to the high mountains in central Japan at 1300 and 1600 JST. At 1900 JST the
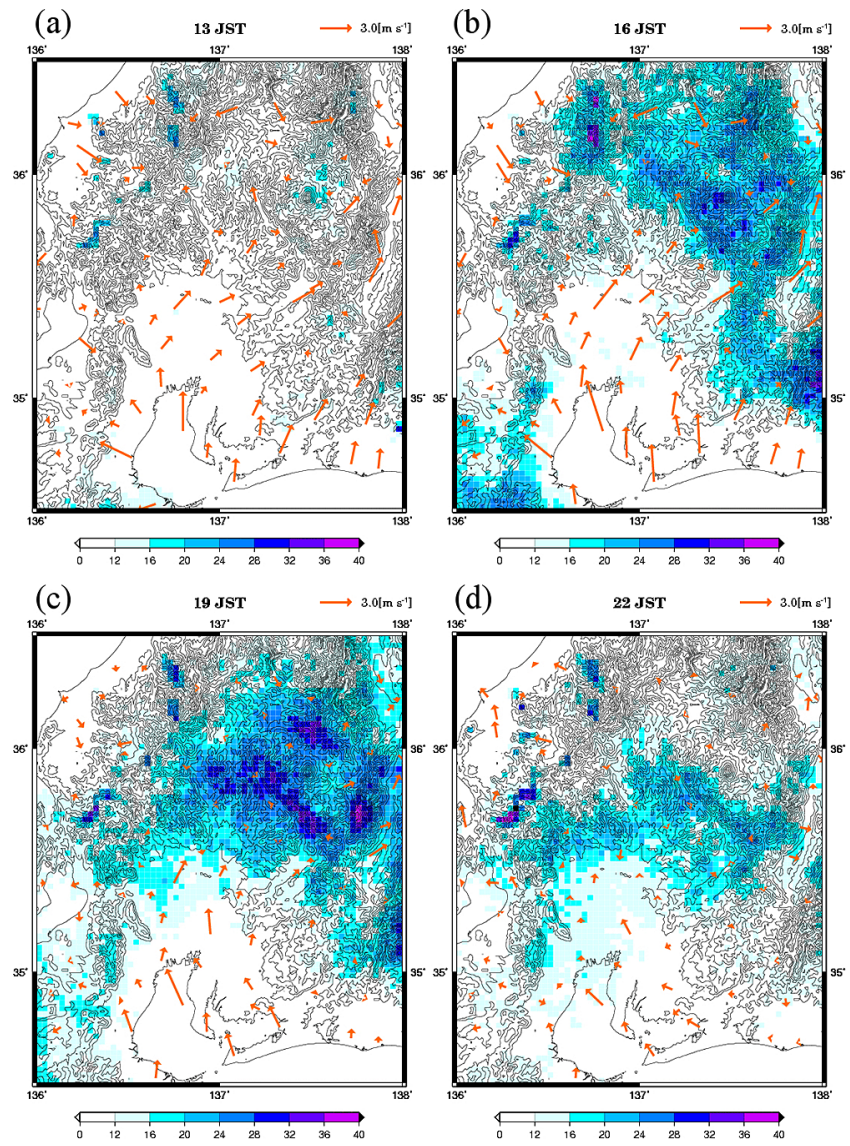

Fig. 2. The frequency distribution of rainfall intensity of greater than or equal to $1 \mathrm{~mm} \mathrm{~h}^{-1}$ at (a) $1300 \mathrm{JST}$, (b) $1600 \mathrm{JST}$, (c) $1900 \mathrm{JST}$, and (d) 2200 JST. The wind vectors averaged over the extracted 137 days are indicated by arrows. The contour lines shows the surface elevation.

southerly wind still exits over the plain, but it ceases at 2200 JST. The eastward flow over the Nobi Plain in the afternoon was identified by Kuwagata (1997) who showed that the flow is due to the influence of thermally induced circulation over central Japan under synoptically undisturbed conditions. Figures $2 \mathrm{a}$ and $2 \mathrm{~b}$ clearly show this feature.

The time sequence of the mean rainfall intensity is demonstrated in Fig. 3. Although the frequency of rainfall is high at higher elevations at 1300 and 1600 JST, Fig. 3a indicates that the intensity of the high-elevation rainfall is very weak. In contrast, the areas of strong rainfall intensity are seen on the slopes of mountains. At 1900 JST strong rainfall intensity is seen in the northern part of the Nobi Plain, but at 2200 JST the intensity over the plain is decreased. These areas with strong rainfall intensity at 1600 and 1900 JST despite lower frequency of rainfall there than at the mountain peaks indicate that the rainfall events tend to be strong when they once develop.

The results shown in Figs. 2 and 3 indicate that there is a high frequency of light rainfall occurrence over high mountains while a low-to-moderate frequency of strong rainfall occurrence over the plain and on mountain slopes.

\section{Environmental conditions}

The extracted 137 days are basically under undisturbed conditions with a high-pressure system to the south of Japan. A close look at the weather maps on the $\mathrm{F}$ days revealed that the location of the center of a high widely varies from east (off the Kanto area) to west (off the Shikoku/Kyushu area). Thus, the F days were further divided into two patterns: one is under the condition of a 

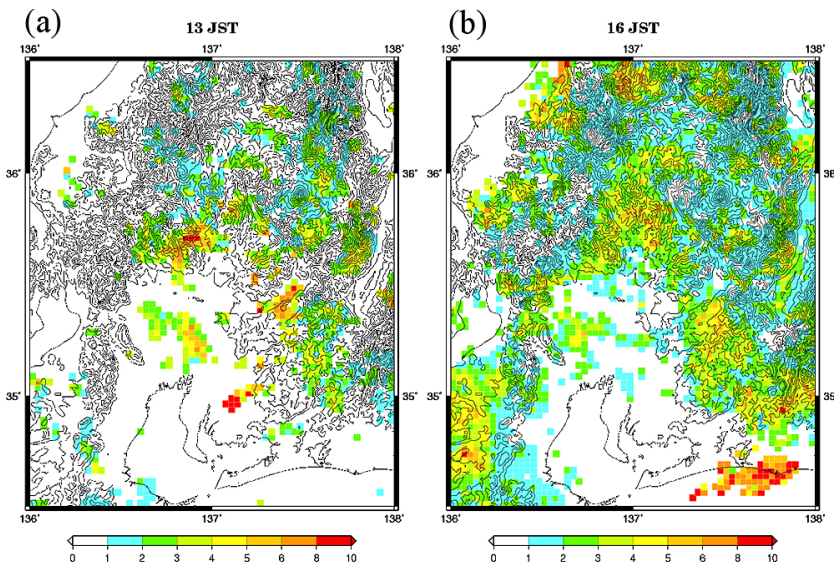

(c)

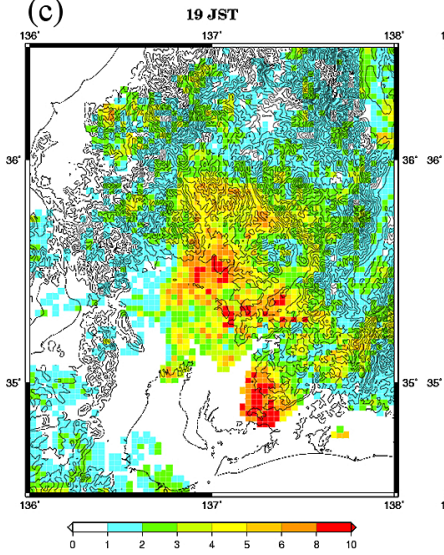

(d)

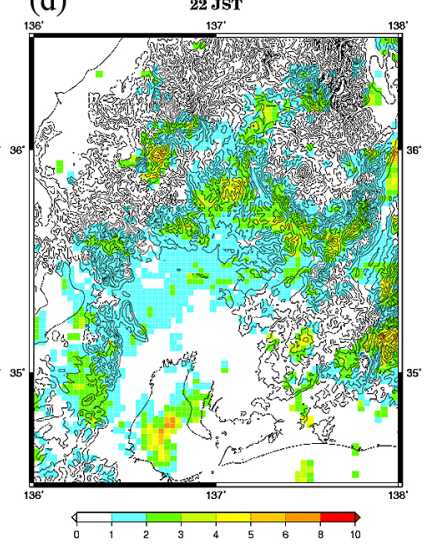

Fig. 3. The same as Fig. 2, except for the distribution of rainfall intensity (in $\mathrm{mm} \mathrm{h}^{-1}$ ) averaged over the extracted days.

high located to the east of the $137.5^{\circ} \mathrm{E}$ line (referred to as $\mathrm{F} / \mathrm{E}$ ); the other is to the west of this line $(\mathrm{F} / \mathrm{W})$. The numbers of the $\mathrm{F} / \mathrm{E}$ and F/W days are 26 and 49, respectively. The mean geopotential height fields at the 700 -hPa level at 0900 JST composited for the $\mathrm{F} / \mathrm{W}, \mathrm{F} / \mathrm{E}$, and $\mathrm{R}$ days are indicated in Fig. 4. On the R days as well as the F/E days a high is shifted eastward, while on the F/W days a high is seen in western Japan.

Because of the large difference in the pressure pattern of the $\mathrm{F} / \mathrm{W}$ days from those of the $\mathrm{F} / \mathrm{E}$ and $\mathrm{R}$ days, it was found that there is a northerly wind component over the Nobi Plain for the

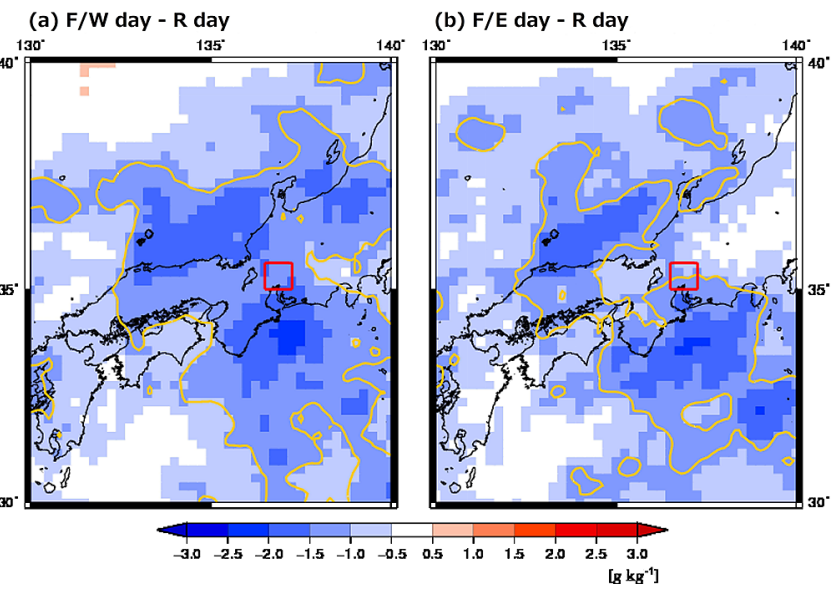

Fig. 5. The differences of (a) the F/W days and (b) the F/E days against the $\mathrm{R}$ days for water vapor mixing ratio at $700 \mathrm{hPa}$ at $0900 \mathrm{JST}$. The orange contour line indicates the differences with statistical significance at the 95\% confidence level.

F/W case. This difference seems to affect the moisture field. Figure 4 also shows the mean fields of water vapor mixing ratio at $700 \mathrm{hPa}$ averaged for the $\mathrm{F} / \mathrm{W}, \mathrm{F} / \mathrm{E}$, and $\mathrm{R}$ days. On the $\mathrm{F} / \mathrm{W}$ days drier air seems to extend from the Sea of Japan southward to the Pacific in central Japan; this leads to a much drier condition over the Nobi Plain for the F/W case than for the other two. Furthermore, the moisture content at $700 \mathrm{hPa}$ in the Nobi Plain for the $\mathrm{R}$ days is higher than that for the $\mathrm{F} / \mathrm{E}$ days. The drier conditions in the F/W and F/E days than in the R days are demonstrated by Fig. 5. It is seen that drier states in the F cases than in the R case, with high statistical significance from t-test statistic, extend in central Japan including the Nobi Plain.

The differences of the mean moisture content averaged in the Nobi Plain for the $\mathrm{R}$ days from the other two cases were also examined by t-test statistic, and it was found that the differences between the $\mathrm{R}$ and F/W cases and also between the $\mathrm{R}$ and F/E cases are statistically significant at the $95 \%$ confidence level. This is also true for the relative humidity at $700 \mathrm{hPa}$; the middle-level atmosphere is moister in the $\mathrm{R}$ days than in the other cases. These statistically significant differences were further found for these quantities at 800 and $850 \mathrm{hPa}$. On the other hand, the differences of temperature between the $\mathrm{R}$ days and the other two were not statistically significant.

The vertical profiles of the mean temperature and relative humidity averaged over the Nobi Plain for the three categories (a) F/W day

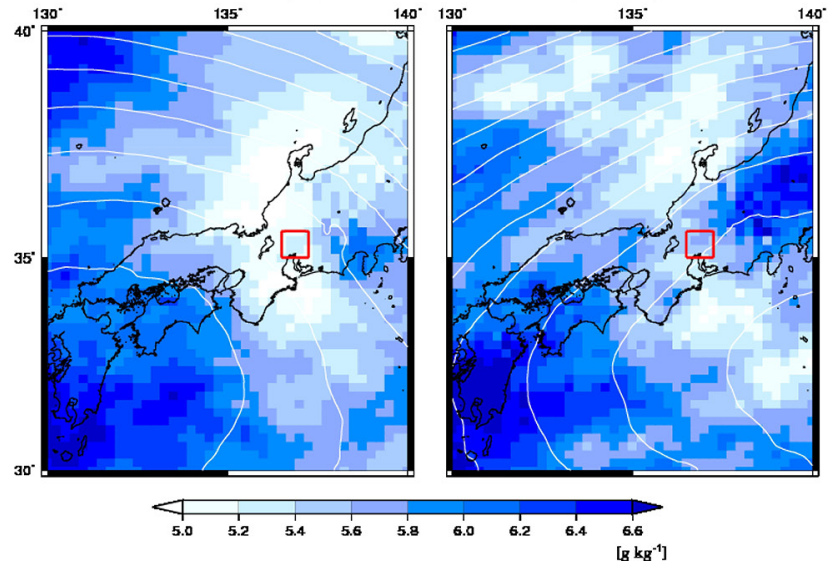

(c) R day

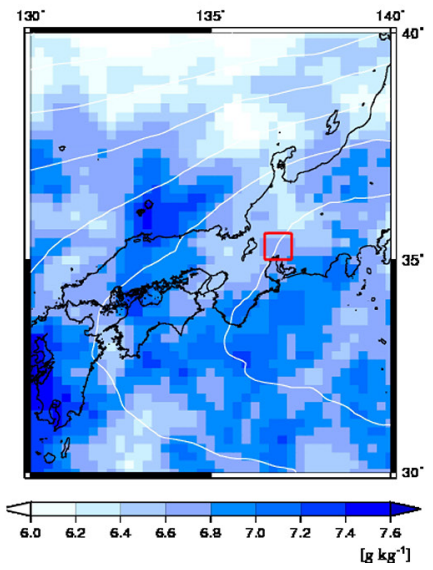

Fig. 4. Mean geopotential height (denoted as white contours at 5-m interval) and water vapor mixing ratio (colored) at the 700-hPa level at 0900 JST composited for the (a) F/W, (b) F/E, and (c) R days. Note that the color bar for (c) is different from that for (a) and (b). The red box denotes the area of the Nobi Plain. 
are compared in Fig. 6. It is seen that the temperature profiles among the categories are nearly the same, while the difference of the relative humidity profiles between the R-day and the F-day are pronounced. Based on these vertical profiles, environmental conditions are examined in terms of some stability indices: convective available potential energy (CAPE), convective inhibition (CIN), Showalter stability index (SSI), lifted index (LI), K-index (KI), and total-totals index (TT) (these definitions can found in Blustein 1993). These parameters are computed with the use of the MSM analyses at each MSM grid and averaged over the grids in the Nobi Plain area. It was found from t-test statistic that there were no significant differences of CAPE and CIN among the three cases at the $95 \%$ confidence level; thus the results for SSI, LI, KI, and TT are shown here.

Figure 7 compares the frequency distribution of SSI, LI, KI, and TT averaged over the Nobi Plain at 0900 JST for the R, F/E, and F/W days by box-and-whisker diagrams. Note that smaller (larger) values of SSI and LI (KI and TT) indicate more unstable states. It is seen that all the indices show more unstable conditions in the $\mathrm{R}$ days than in the other two, with the F/W cases being the most stable. Although the range of the maximum and the minimum overlaps among the three categories, the mean, the median, and the 25 and 75 percentiles unanimously indicate more unstable states in the $\mathrm{R}$ case than in the others. It was found that the differences between the $\mathrm{R}$ and $\mathrm{F} / \mathrm{W}$ days for all the four indices were statistically significant. In contrast, the differences between the $\mathrm{R}$ and F/E days for all the indices were not significant; however, the difference of KI was close to be significant.

This statistical significance test shows that KI indicates the highest significance level among the four indices. Because KI is determined by the temperature difference between 850 and $500 \mathrm{hPa}$, the $700-\mathrm{hPa}$ temperature, and dew points at 850 and
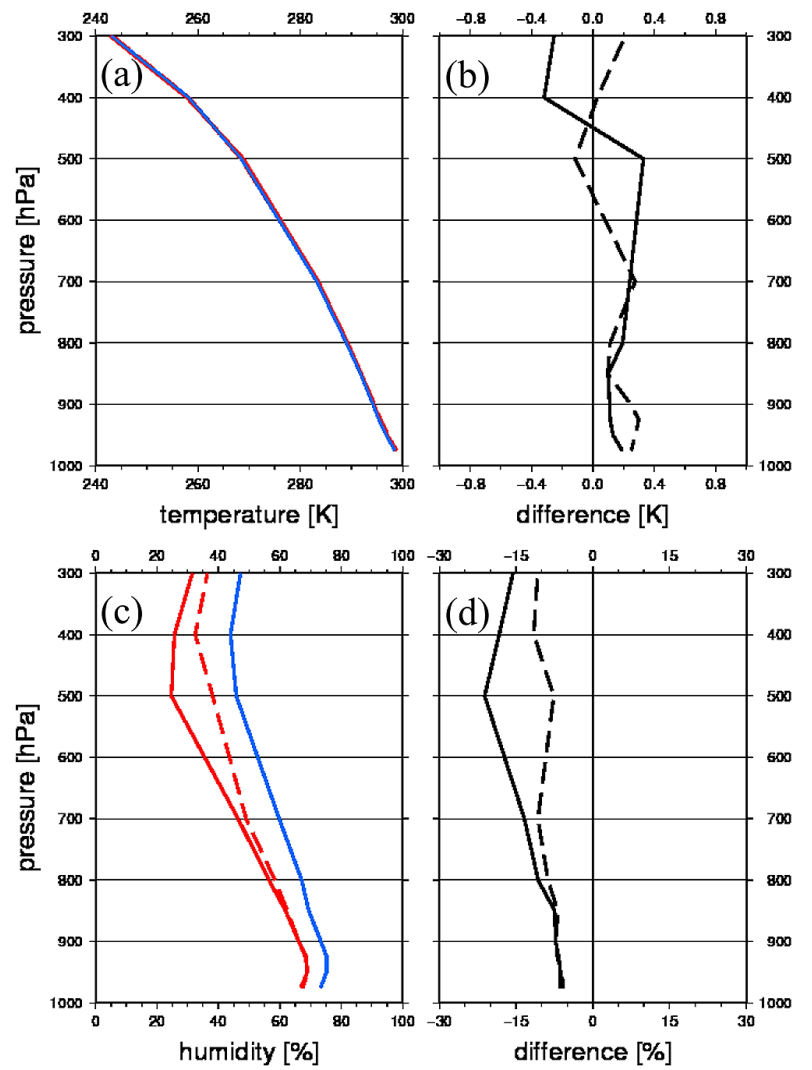

Fig. 6. The vertical profiles of the mean (a) temperature and (c) relative humidity averaged over the Nobi Plain for the R-day (blue solid line), the $\mathrm{F} / \mathrm{W}$ day (red solid line), and the F/E day (red dashed line), and the (b) temperature and (d) relative humidity differences of the F/W day (solid line) and the F/E day (dashed line) against the R-day, obtained from the radiosonde observations at $0900 \mathrm{JST}$.
$700 \mathrm{hPa}$, the differences of temperature and relative humidity at these heights plays a role. From Figs. 5 and 6, the difference of relative humidity is statistically significant at the low levels below the 700-hPa level, which leads to the significant difference of KI. On the other hand, since the differences of temperature at each height between the $\mathrm{R}$ and $\mathrm{F}$ days were not statistically significant, the temperature terms in the KI definition decrease the significance level.

\section{Conclusions}

This study investigated the behavior of summertime afternoon rainfall and its environmental conditions over the Nobi Plain with the use of operational meteorological data. Data from 2003 to 2010 were statistically examined. The analysis on the spatial and temporal characteristics of rainfall in and around the Nobi Plain under synoptically undisturbed conditions indicated that strong rainfall occurs in the northern part of the Nobi Plain in early evening as well as over the mountain slopes in late afternoon. In contrast, light rain frequently occurs around the mountain peaks in early afternoon. By using the analysis precipitation dataset, we were successful in demonstrating the fine-scale characteristics of rainfall distribution in and around the Nobi Plain.

The examination of the MSM data revealed that the primary difference in the environmental conditions that distinguish from the rain occurrences to the no-rain cases is the moisture content at the middle levels over the Nobi Plain as well as its surroundings. Both water vapor content and relative humidity are higher in the rain cases than in the fair-weather cases. Because of the significant difference in middle-level moisture, $\mathrm{K}$-index significantly distinguishes the environmental conditions between the rain and the (a)

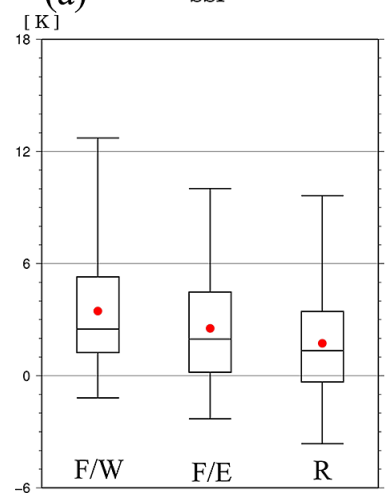

(c)

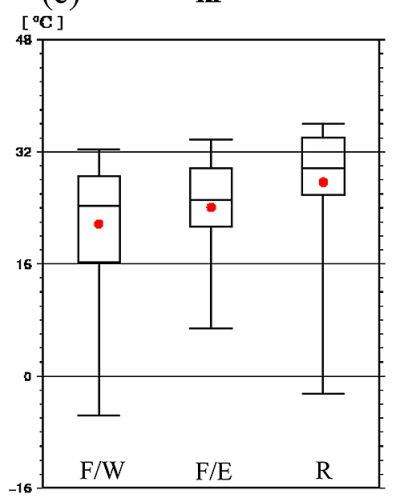

(b)

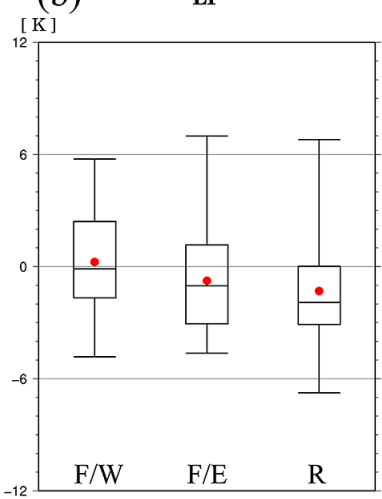

(d)

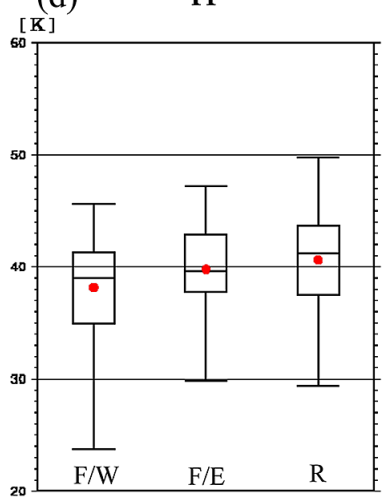

Fig. 7. The box-and-whisker plot of (a) SSI, (b) LI, (c) KI, and (d) TT averaged in the Nobi Plain area at 0900 JST for the F/W, F/E, and R days. The whiskers at the upper and lower ends denotes the maximum and the minimum, respectively. The top, bottom, and middle lines of the box indicate the 75,25 percentile values, and the median values, respectively. The red dots show the mean values. 
no-rain cases. It was also found that the fair-weather conditions can be divided into two patterns depending on the location of the Pacific high. When the center of the high is located in western Japan, the condition becomes quite dry at middle levels, which would strongly suppress the occurrence of rainfall over the Nobi Plain.

This study also demonstrates the utility of the MSM data for the analysis of mesoscale climatological environments for convective rainfalls, as was done in NT11. Since the accuracy of MSM data is continuously improving, the MSM data are useful for the climatological analysis of convective rainfalls in various regions in Japan. Complex terrain features of Japan are considered to affect the development and evolution of convective rainfalls from region to region, but also it is reasonable to assume that there would be some similarities. By conducting such analyses, commonality and locality of such rainfalls throughout Japan will be revealed. The use of MSM data should be conducted more extensively.

The analysis on environmental conditions for convective precipitation can be extended to investigate the environmental characteristics in future climates under global warming (Takemi et al. 2012).

\section{Acknowledgements}

The comments by two anonymous reviewers and the editor are acknowledged in improving the original manuscript. The MSM data were obtained from a database at Research Institute for Sustainable Humanosphere, Kyoto University. The radiosonde data were obtained though the web site of the University of Wyoming at http://weather.uwyo.edu/upperair/sounding.html.

\section{Supplement}

Supplement 1 shows the comparison of the MSM analyses with the radiosonde observations.

\section{References}

Bluestein, H. B., 1993: Synoptic-Dynamic Meteorology in Midlatitudes, Vol. II, Oxford Univ. Press, 594 pp.

Kawano, K., Y. Hirokawa, and H. Ohno, 2004: Diagnosis of airmass thunderstorm days using radiosonde data: The summer Kanto area under the Pacific subtropical anticyclone. Tenki, 51, 17-30.

Kobayashi, F., T. Takano, and T. Takamura, 2011: Isolated cumulonimbus initiation observed by $95-\mathrm{GHz}$ FM-CW radar,
$\mathrm{X}$-band radar, and photogrammetry in the Kanto region, Japan. SOLA, 7, 125-128.

Kuwagata, T., 1997: An analysis of summer rain showers over central Japan and its relation with the thermally induced circulation. J. Meteor. Soc. Japan, 75, 513-527.

Nagata, K., 2011: Quantitative precipitation estimation and quantitative precipitation forecasting by the Japan Meteorological Agency. RSMC Tokyo-Typhoon Center Technical Review, 13, 37-50. Available online at: http://www.jma.go.jp/jma/jmaeng/jma-center/rsmc-hp-pub-eg/techrev/text13-2.pdf.

Nomura, T., and T. Takemi, 2011: Environmental stability for afternoon rain events in the Kanto Plain in summer. SOLA, 7, 9-12.

Obana, R., 1977: The influence of topography on locally heavy rainfall in the Tokai region (I). Tenki, 24, 37-43. (in Japanese)

Saito, S., K. Kusunoki, and H. Y. Inoue, 2013: A case study of merging of two misocyclones in the TOMACS field campaign area of Tokyo on 26 August 2011. SOLA, 9, 153-156.

Sakurai, N., K. Iwanami, T. Maesaka, S. Suzuki, S. Shimizu, R. Misumi, D. Kim, and M. Maki, 2012: Case study of misoscale convective echo behavior associated with cumulonimbus development observed by Ka-band Doppler radar in the Kanto region, Japan. SOLA, 8, 107-110.

Sano, T., and K. Tsuboki, 2006: Structure and evolution of a cumulonimbus cloud developed over a mountain slope with the arrival of sea breeze in summer. J. Meteor. Soc. Japan, 84, 613-640.

Shoji, Y., 2013: Retrieval of water vapor inhomogeneity using the Japanese nationwide GPS array and its potential for prediction of convective precipitation. J. Meteor. Soc. Japan, 91, $43-62$.

Taguchi, A., K. Okuyama, and Y. Ogura, 2002: The thunderstorm activity observed by SAFIR and its relation to the atmospheric environment over the Kanto area in the summer. Part II: Thunderstorm prediction by stability indices. Tenki, 49, 649-659. (in Japanese)

Takemi, T., S. Nomura, Y. Oku, and H. Ishikawa, 2012: A regional-scale evaluation of changes in environmental stability for summertime afternoon precipitation under global warming from super-high-resolution GCM simulations: A study for the case in the Kanto Plain. J. Meteor. Soc. Japan, 90A, 189212.

Yonetani, T., 1975: Characteristics of atmospheric vertical structure on days with thunderstorms in the northern Kanto Plain. J. Meteor. Soc. Japan, 53, 139-148.

Manuscript received 16 June 2014, accepted 3 September 2014

SOLA: https://www.jstage.jst.go.jp/browse/solal 